\title{
PENGARUH HEDONIC VALUES DAN UTILITARIAN VALUES PADA KEPUASAN KONSUMEN DAN BEHAVIOURAL INTENTIONS PADA RESTORAN FAST FOOD DI SURABAYA
}

\author{
Arief Sosiawan \& I Kadek Oka Swartana \\ Universitas Surabaya \\ ikadek_okas@yahoo.com
}

\begin{abstract}
This paper aims to examine the influence of hedonic and utilitarian values values on consumer satisfaction and behavioural intentions at a fast food restaurant in Surabaya. The methods used in selecting respondents used sampling methods i.e. convenience sampling, a total of 115 respondents whose data is being processed. The model research of using Smart PLS 4.0 to test the hypothesis. The result of the research shows that there is a significant relationship, namely the relationship between: Hedonic value with Behavioural intentions, Hedonic value with consumer satisfaction, consumer satisfaction with Behavioural intentions, utilitarian value with consumer satisfaction. Meanwhile there is no relationship between the utilitarian value with the behavioural intentions. The contribution of research to the theory through the development of the value of customer satisfaction that is hedonic and utilitarian.
\end{abstract}

Keywords: values, hedonic utilitarian values, consumer satisfaction, behavioural intentions and fast food restaurants.

\begin{abstract}
Abstrak
Paper ini bertujuan untuk menguji pengaruh hedonic values dan utilitarian values pada kepuasan konsumen dan behavioural intentions pada restoran fast food di Surabaya. Metode yang digunakan dalam memilih responden digunakan metode sampling yaitu konvenien sampling, total 115 responden yang datanya diolah. Model penelitian menggunakan Smart PLS4.0 untuk menguji hipotesis. Hasil dari penelitian menunjukkan bahwa terdapat hubungan yang signifikan yaitu hubungan antara: Hedonic value dengan Behavioural intentions, Hedonic value dengan Kepuasan konsumen, Kepuasan konsumen dengan Behavioural intentions, utilitarian value dengan Kepuasan konsumen. Sementara itu tidak ada hubungan antara utilitarian value dengan behavioural intentions. Kontribusi penelitian ini untuk teori melalui pengembangan nilai kepuasan konsumen yaitu hedonic dan utilitarian.
\end{abstract}

Kata kunci: hedonic values, utilitarian values, kepuasan konsumen, behavioural intentions dan restoran fast food. 


\section{Arief Sosiawan}

\section{Kadek Oka Swartana}

\section{Pendahuluan}

Penelitian ini bertujuan untuk untuk menguji pengaruh hedonic values dan utilitarian values pada kepuasan konsumen dan perilaku niat (behavioural intentions) pada fast food restaurants di Surabaya). Motivasi dari penelitian ini adalah saat ini di Surabaya banyak sekali tempat kuliner yang buka, baik itu restoran, café maupun warung kopi, selain itu juga untuk mengamati apakah konsumen puas serta bagaimana perilaku niat konsumen terhadap restoran fast food.

Bagi para pekerja maupun mahasiswa, yang setiap harinya harus berangkat pagi hari dan pulang hingga sore hari, akan berhadapan dengan masalah bagaimana bisa makan siang, tatkala mereka tidak membawa bekal dari rumah. Sebenarnya kalau mereka membawa bekal dari rumah, tidak akan bingung untuk makan siangnya, selain itu dari sisi proses memasak maupun bahan-bahan yang digunakan tentunya sudah merupakan pilihan terbaik. Namun dalam realisasinya mempunyai kendala dari sisi waktu memasaknya. Berdasar kondisi seperti ini, maka kebanyakan orang akan memilih makan siang di luar. Makanan cepat saji (fast food) telah menjadi pilihannya, dengan alasan cepat memasaknya dan menyajikannya, namun yang perlu dipertimbangkan adalah dari segi kesehatan. Karena tidak semua dapat mengkonsumsi masakan cepat saji, ada orang yang tidak diperbolehkan makan gorengan, terdapat orang yang tidak bisa makan masakan yang ada MSG-nya.

Keberadaan restoran fast food merupakan salah satu industri dengan pertumbuhan tercepat secara global, termasuk di Surabaya, disamping saat ini juga banyak kafé maupun PKL yang muncul dengan menyajikan makan cepat saji. Menurut Tjahjono, Ketua Asosiasi Pengusaha Kafe dan Restoran Indonesia (Apkrindo) Jawa Timur (kabarbisnis.com), secara umum pertumbuhan bisnis kafe dan restoran di kota pahlawan ini masih menjanjikan, selain itu juga omset bisnis restoran di Surabaya cukup besar. Dari hitungan kasarnya, tiap bulan omset bisnis restoran yang tergabung dalam Apkrindo saja, berjumlah sekitar 100 restoran dan kafe, bisa mencapai Rp 30 miliar. Hitungan kasarnya, tiap resto omsetnya Rp 300 juta per bulan, sedangkan yang sudah bergabung dengan Apkrindo berjumlah sekitar 100 restoran.

Perilaku konsumen berkaitan dengan pembelian makanan pada umumnya dipengaruhi oleh perubahan yang dikarenakan faktor peningkatan pendapatan, gaya dan pola hidup, tingkat pendidikan, interaksi global, informasi dan teknologi komunikasi. Dengan memeriksa 


\section{Jurnal Manajemen Teori dan Terapan \\ Tahun 11. No. 1, April 2018}

hubungan antara tiga elemen dari nilai (yaitu kualitas inti, relasional kualitas dan layanan nilai), kepuasan pelanggan dan masa depan di seluruh empat Layanan (dokter gigi, penata rambut, auto perbaikan dan restoran), McDougall dan Levesque (2000) mendapatkan temuan, bahwa semua variabel tiga inti kualitas, kualitas relasional dan layanan nilai significan mempengaruhi kepuasan pelanggan, yang pada gilirannya hasil di masa depan. Mereka menunjukkan bahwa nilai (values) yang dirasakan memiliki dampak terbesar pada permintaan potensial untuk Restoran, dibandingkan dengan sektor lain diinvestigasi.

Apa yang membedakan restoran cepat (fast-casual restaurant) dengan rentoran cepat saji (casual dining segment), adalah merupakan janji dari restoran cepat untuk menawarkan kualitas makanan lebih tinggi dan suasana daripada restoran cepat saji, yang lebih konsisten dengan segmen bersantap kasual (Ryu et al., 2010) . Ritzer (2001) berpendapat bahwa meskipun restoran cepat saji tidak begitu efisien dan murah dibandingkan dengan makan di rumah, industri makanan cepat telah sukses di seluruh dunia. Ia berkaitan ini ilusi efisiensi dan berhemat oleh orang-orang, ditambah dengan bagian yang menyenangkan dan hiburan untuk bersantap di restoran tersebut. Karena perilaku konsumen yang didorong oleh pertimbangan utilitarian dan hedonic, mereka dapat mempengaruhi pilihan konsumen. Dibandingkan dengan aspek-aspek utilitarian, nilai sisi "perayaan" telah menerima perhatian kurang dalam studi sebelumnya dan Arnold dan Reynolds (2003) berpendapat bahwa penelitian akademis yang tertinggal dalam menyelidiki sisi hedonic.

Penelitian ini mengangkat beberapa rumusan masalah, adapun rumusan masalah tersebut (1)apakah hedonic value pengalaman bersantap yang dampak positif pada lkepuasan pelanggan ? , (2) apakah ultilitarian value pengalaman bersantap yang memiliki dampak positif pada kepuasan pelanggan ?, (3) apakah hedonic value pengalaman bersantap yang memiliki dampak positif pada prilaku niat ? , (4) apakah utilitarian value pengalaman bersantap yang memiliki dampak positif pada prilaku niat ?, (5) apakah kepuasan pelanggan memiliki dampak positif pada prilaku niat di segmen restoran cepat saji? (6)apakah utilitarian value yang dirasakan memiliki pengaruh yang lebih kuat pada kepuasan pelanggan daripada hedonic value yang dirasakan di segmen restoran cepat saji ?.

Tujuan dan manfaat yang dapat diambil dalam penelitian ini adalah (1) untuk mengetahui apakah hedonic value pengalaman bersantap yang memiliki dampak positif pada kepuasan pelanggan, (2) untuk mengetahui apakah utilitarian value pengalaman bersantap yang memiliki dampak positif pada kepuasana pelanggan, (3) untuk megetahui apakah hedonic value pengalaman bersantap yang memiliki dampak positif pada prilaku niat, (4) untuk mengetahui apakah utilitarian value pengalaman bersantap yang memiliki 


\section{Arief Sosiawan}

\section{Kadek Oka Swartana}

dampak positif pada prilaku niat, (5) untuk mengetahui apakah kepuasan pelanggan memiliki dampak positif pada prilaku niat di segmen restoran cepat saji, (6) untuk mengetahui apakah utilitarian value yang dirasakan memiliki influence yang lebih kuat pada kepuasan pelanggan daripada hedonic value yang dirasakan di segmen resroran cepat saji.

\section{Tinjauan Pustaka}

Banyak penelitian telah dilakukan dan menghasilkan bahwa nilai memiliki pengaruh signifikan pada kepuasan pelanggan dan perilaku niat (McDougall dan Levesque, 2000; Pura, 2005; Chen dan Tsai, 2007; Lee et al., 2007). Studi sebelumnya dalam makanan Layanan (Johns dan Tyas, 1996) memiliki konfirmasiterkait dengan kepuasan yang mengarah ke niat perilaku yang positif, seperti pembelian kembali. Selain itu, hubungan yang positif antara nilai yang dirasakan dan niat untuk pembelian kembali telah diteliti oleh Parasuraman dan Grewal,( 2000). Apa yang membedakan restoran cepat dengan makanan cepat (fast-casual restaurant), adalah merupakan janji dari restoran cepat untuk menawarkan kualitas makanan lebih tinggi dan suasana daripada restoran cepat saji (casual dining segment), yang lebih konsisten dengan segmen. Prilaku konsumen yang didorong oleh pertimbangan utilitarian dan hedonic, mereka dapat mempengaruhi pilihan konsumen. Dibandingkan dengan aspek-aspek utilitarian, nilai sisi "perayaan" telah menerima perhatian kurang dalam studi sebelumnya dan Arnold dan Reynolds (2003) bersantap kasual (Ryu et al., 2010). Nejati et al 2013 meneliti pengaruh nilai hedonic dan utilitarian pada kepuasan konsumen dan perilaku niat.

\section{Hipotesis Penelitian}

Hla: Hedonic value pengalaman bersantap yang memiliki dampak positif pada kepuasan pelanggan.

H1b: Utilitarian value pengalaman bersantap yang memiliki dampak positif pada kepuasan pelanggan.

H2a: Hedonic value pengalaman bersantap yang memiliki dampak positif pada niat perilaku..

H2b: Utilitarian value pengalaman bersantap yang memiliki dampak positif pada niat perilaku.

H3 : Kepuasan pelanggan memiliki dampak positif pada niat perilaku di segmen restoran cepat. 


\section{Metode Penelitian}

Penelitian ini merupakan penelitian dengan menggunakan kuesioner, dengan responden sebagai sampel penelitian yang digunakan adalah mahasiswa program sarjana dan master serta para pekerja dan professional serta konsultan yang ada di Surabaya. Dalam memilih responden digunakan metode sampling yaitu konvenien sampling yaitu responen yang siap dan mau dijadikan responden dan bersedia mengisi kuesioner dengan kata lain respondennya bersifat volunteer. Sampel penelitian dalam penelitian ini terdapat 115 sampel dengan range usia antara 19-64 tahun.

\section{Diskusi}

Terdapat 115 kuesioner yang terisi lengkap yang dipertimbangkan serta digunakan untuk analisis akhir. Rata-rata responden $85 \%$, dimana $15 \%$ dari responden tidak mengisi lengkap sehingga dikeluarkan dari penelitian ini. Range usia responden antara 19 - 64 tahun, dan $67 \%$ dari responden adalah berjenis kelamin laki-laki. Pendidikan akhir responden sebagaian besar sebesar $64 \%$ lulusan S1 dan pekerjaan atau profesi responden sebagaian besar adalah Karyawan swasta sebesar $71 \%$ serta penghasilan responden yang paling banyak ada pada posisi kurang dari Rp.5.000.000,- yaitu sebesar 60\%.

\section{Pengujian Model}

Pada penelitian ini langkah atau step yang kedua adalah menguji secara kuantitatif dengan alat analisis statistik yang digunakan adalah Structural Equation Modelling (SEM). SEM merupakan gabungan dari dua metedologi disiplin ilmu yaitu perspektif ekonometrika yang focus pada prediksi dan psychometrika yang mampu untuk menggambarkan konsep model dengan variable laten (variabel yang tidak dapat diukur secara langsung) tetapi diukur melalui indikator-indikatornya (Latan dan Ghozali, 2014). Tehnik SEM yang digunakan dalam penelitian ini dengan menggunakan software WarpPLS (Part Least Square). PLS sering disebut juga sebagai soft modelling karena tidak memerlukan asumsi-asumsi Ordinary Least Square (OLS), seperti data yang harus berdistribusi normal, tidak adanya multikolinearitas, dan asumsi-asumsi lain (Latan dan Ghozali, 2014). Penggunaan alat analisis statistik SEM-PLS software WarpPLS dalam penelitian ini dengan pertimbangan bahwa alat analisis inilah yang dinilai tepat digunakan pada penelitian ini. Model Pengukuran (Outer Model) 


\section{Arief Sosiawan}

\section{Kadek Oka Swartana}

\section{Model Struktural (Inner Model)}

Menurut Latan dan Ghozali, (2012), evaluasi model structural atau Inner Model menunujukkan kekuatan estimasi antar variable laten. Inner Model dievaluasi dengan melihat besar presentase variance yang dijelaskan pada nilai sebagai berikut:

1) R-Square

R-Square untuk konstruk laten endogen, ketentuan dari R-Square adalah R-Square 0.75; 0.50; 0.25 diartikan bahwa model tersebut adalah kuat; moderate; lemah. Selain melihat besarnya R-Square, evaluasi inner model juga dilakukan dengan melihat besarnya nilai Q-Square predictive relevance.

2) Uji †

Pengujian hipotesis yang dilakukan engan metode bootstrap yang menggunakan Tstatistik atau uji t sebagai statistik uji. Pendekatan bootstrap merepresentasikan non parametric untuk precision dari estimasi PLS. Kriteria pengujian uji $\dagger$ apabila $\dagger>1,96$ (valid) berpengaruh secara signifikan.

\section{Diskusi}

Berdasarkan data tabulasi hasil jawaban dari responden setelah diolah dengan menggunakan uji statistik smart PLS, nampak model penelitian sebagai berikut: Gambar 1, menunjukkan model setelah dilakukan uji statistic dengan menggunakan Smart PLS, ternyata terdapat satu indikator pada variabel Utilitarian value, yaitu yang menyatakan bahwa makan di restoran fast food, pelayanannya cepat, karena hasilnya menunjukkan nilai di atas 1,035. Gambar 2, merupakan model setelah dilakukan validasi 


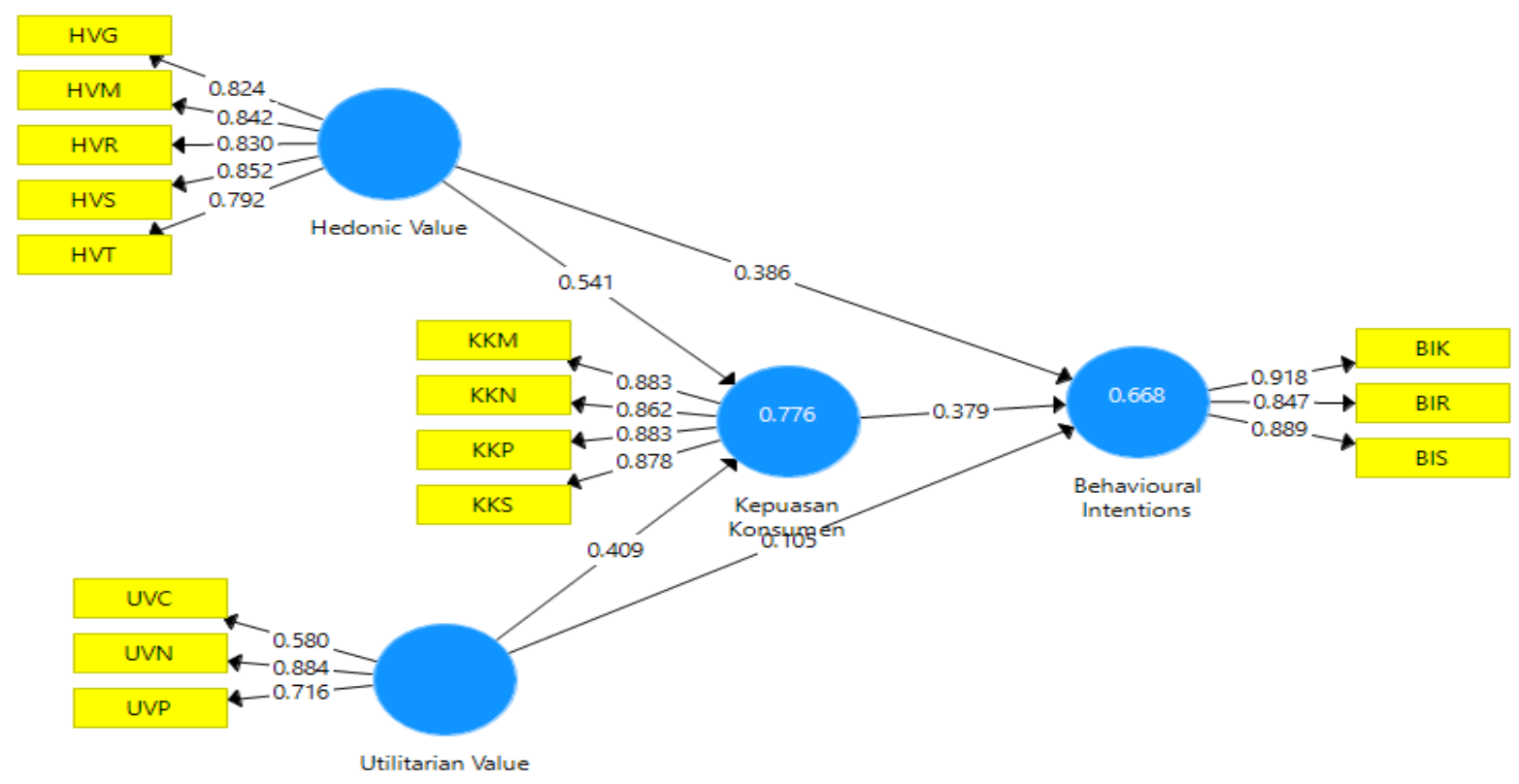

Gambar 1. Model Modifikasi

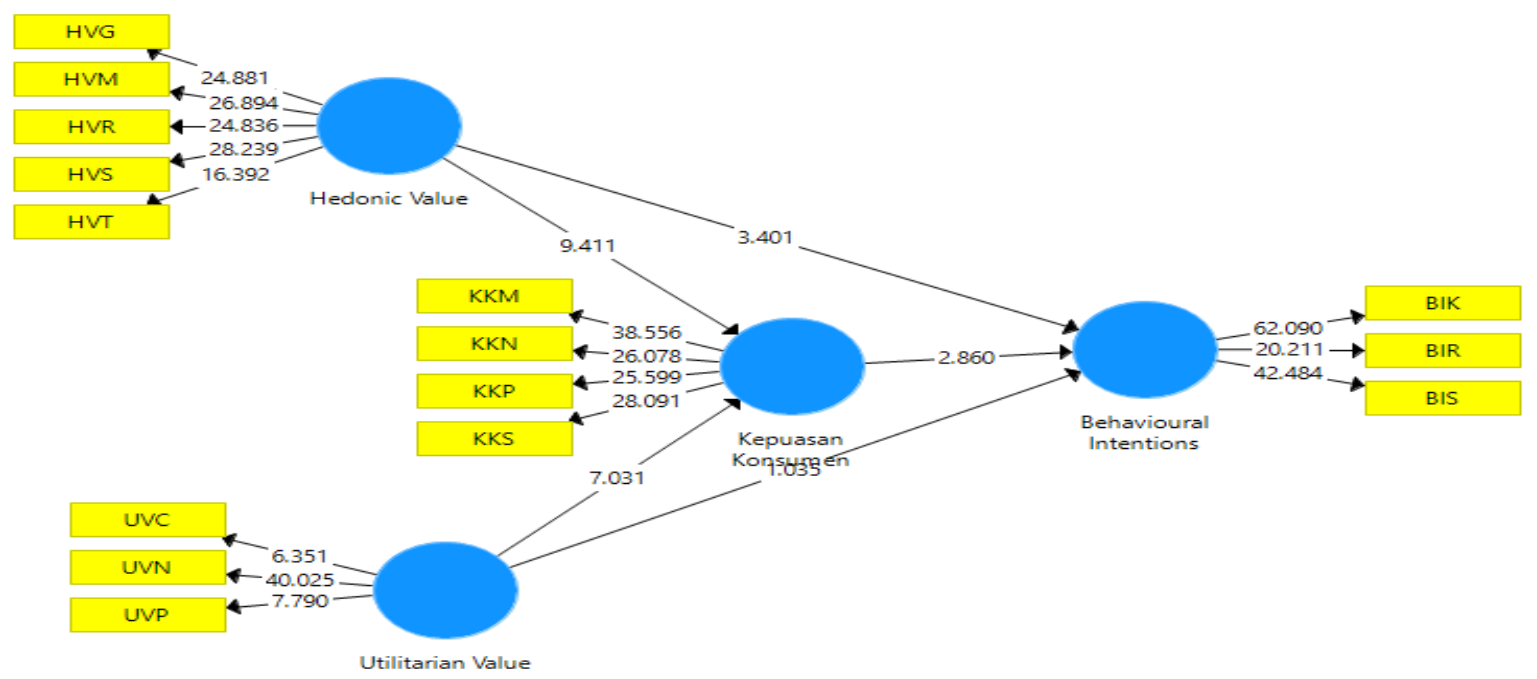

Gambar 2. Model Bootstrap

Tabel 1, menunjukkan Loading factor dengan ketentuan nilainya 0,4, hasil penelitian ini semua indikator menunjukkan nilai di atas 0,4, dengan demikian semua indicator dapat digunakan.

Berdasar tabel 2, dengan ketentuan nilai composite reliability sebesar $>0,7$, dan tabel tersebut semua variabel: Behavioural Intentions, Hedonic Value, Kepuasan Konsumen dan 


\section{Arief Sosiawan}

\section{Kadek Oka Swartana}

Utilitarian Value, menunjukkan angka composite reliability dengan angka di atas 0,7. Hal ini menunjukkan semua variabel yang digunakan semua reliable.

Sedangkan untuk Average Variance Extracted (AVE) yang digunakan untuk menguji validitas variabel dengan ketentuan nilai > 0,5, menunjukkan semua variabel yang digunakan dalam penelitian, yaitu Behavioural Intentions, Hedonic Valve, Kepuasan Konsumen dan Utilitarian Value,kesemuanya memiliki nilai di atas 0,5, dengan demikian semua variabel valid.

Nilai R-square menunjukkan berapa presentase variasi konstruk endogen dapat dijelaskan oleh konstruk yang dihipotesiskan mempengaruhinya (eksogen). Berdasarkan tabel 3, dan ketentuan nilai R-square Adjusted > 0.05, maka dapat dilihat pada Behavioural intentions Rsquare Adjusted 0.659, hal ini menunjukkan bahwa Hedonic value sama utilitarian value terhadap Behavioural intentions, hasilnya baik. Demikian juga dengan Hedonic value sama utilitarian value terhadap kepuasan konsumen, dengan nilai R-square Adjusted sebesar 0.772 , berarti hasilnya baik, karena nilainya di atas 0.05 .

Tabel 1. Outer model

\begin{tabular}{|c|c|c|c|c|}
\hline & $\begin{array}{l}\text { Behavioural } \\
\text { Intentions }\end{array}$ & Hedonic Value & $\begin{array}{l}\text { Kepuasan } \\
\text { Konsumen }\end{array}$ & Utilitarian Value \\
\hline BIK & 0.918 & & & \\
\hline BIR & 0.847 & & & \\
\hline BIS & 0.889 & & & \\
\hline HVG & & 0.824 & & \\
\hline HVM & & 0.842 & & \\
\hline HVR & & 0.830 & & \\
\hline HVS & & 0.852 & & \\
\hline HVT & & 0.792 & & \\
\hline KKM & & & 0.883 & \\
\hline $\mathrm{KKN}$ & & & 0.862 & \\
\hline KKP & & & 0.883 & \\
\hline KKS & & & 0.878 & \\
\hline UVC & & & & 0.580 \\
\hline UVN & & & & 0.884 \\
\hline UVP & & & & 0.716 \\
\hline
\end{tabular}

Tabel 2. AVE 


\begin{tabular}{lrrrr}
\hline & $\begin{array}{c}\text { Cronbach's } \\
\text { Alpha }\end{array}$ & rho_A & $\begin{array}{c}\text { Composite } \\
\text { Reliability }\end{array}$ & $\begin{array}{c}\text { Average } \\
\text { Variance } \\
\text { Extracted (AVE) }\end{array}$ \\
\hline Behavioural Intentions & 0.861 & 0.869 & 0.915 & 0.783 \\
Hedonic Value & 0.885 & 0.886 & 0.916 & 0.686 \\
Kepuasan Konsumen & 0.899 & 0.901 & 0.930 & 0.768 \\
Utilitarian Value & 0.574 & 0.659 & 0.776 & 0.543 \\
\hline
\end{tabular}

Berdasar tabel 4, dengan ketentuan nilai $\dagger$ statistic apabila $<=1,96$ menunjukkan hubungan antar variabel tidak signifikan dan apabila † statistic >1,96 menunjukkan hubungan antar variabel signifikan. Pada tabel 4, menunjukkan bahwa terdapat satu nilai t statistic dengan angka 1.035 yang menunjukkan bahwa hubungan utilitarian value dengan behavioural intentions tidak signifikan. Sementara nilai yang lain semua di atas 1,96 berarti menunjukkan hubungan yang signifikan yaitu hubungan antara: Hedonic value dengan Behavioural intentions, Hedonic value dengan Kepuasan konsumen, Kepuasan konsumen dengan Behavioural intentions, utilitarian value dengan Kepuasan konsumen.

Tabel 3. R Square

\begin{tabular}{lll}
\hline & R Square & R Square Adjusted \\
\hline Behavioural intentions & 0.668 & 0.659 \\
Kepuasan konsumen & 0.776 & 0.772 \\
\hline
\end{tabular}

Berdasar hasil dari hasil hubungan utilitarian value dengan behavioural intentions tidak signifikan, menggambarkan bahwa niali-nilai manfaat yang terdapat pada restorant fast food ternyata tidak mempengaruhi pelanggan untuk kembali, merekomendasi maupun kunjungan kembali pelanggan pada restorant fast food.

Berdasarkan tabel 4 dengan ketentuan nilai $P$ value apabila $>0,05$ menunjukkan hubungan antar variabel tidak ada pengaruh dan apabila $P$ value < menunjukkan hubungan antar variabel terdapat pengaruh. Pada tabel 5 , menunjukkan bahwa terdapat satu nilai $P$ value dengan angka 0.301 berarti nilainya lebih besar dari 0,05 yang menunjukkan bahwa tidak ada hubungan antara utilitarian value dengan behavioural intentions. Sementara nilai yang lain semua di bawah angka 0,05 berarti menunjukkan hubungan yang signifikan yaitu hubungan antara: Hedonic value dengan Behavioural intentions, Hedonic value dengan Kepuasan konsumen, Kepuasan konsumen dengan Behavioural intentions, utilitarian value dengan Kepuasan konsumen.

Tabel 4. Path Coefficient 


\begin{tabular}{lccccc}
\hline & $\begin{array}{c}\text { Original } \\
\text { Sample } \\
(\mathbf{O})\end{array}$ & $\begin{array}{c}\text { Sample } \\
\text { Mean } \\
(\mathbf{M})\end{array}$ & $\begin{array}{c}\text { Standard } \\
\text { Deviation } \\
(\text { STDEV })\end{array}$ & $\begin{array}{c}\text { T Statistics } \\
(\mid \mathbf{O} / \text { STDEV } \mid)\end{array}$ & $\begin{array}{c}\mathbf{P} \\
\text { Values }\end{array}$ \\
\hline $\begin{array}{l}\text { Hedonic Value -> Behavioural } \\
\text { Intentions }\end{array}$ & 0.386 & 0.386 & 0.114 & 3.401 & 0.001 \\
$\begin{array}{l}\text { Hedonic Value -> Kepuasan } \\
\text { Konsumen }\end{array}$ & 0.541 & 0.540 & 0.058 & 9.411 & 0.000 \\
$\begin{array}{l}\text { Kepuasan Konsumen -> } \\
\text { Behavioural Intentions }\end{array}$ & 0.379 & 0.368 & 0.133 & 2.860 & 0.004 \\
$\begin{array}{l}\text { Utilitarian Value -> Behavioural } \\
\text { Intentions }\end{array}$ & 0.105 & 0.115 & 0.101 & 1.035 & 0.301 \\
$\begin{array}{l}\text { Utilitarian Value -> Kepuasan } \\
\text { Konsumen }\end{array}$ & 0.409 & 0.409 & 0.058 & 7.031 & 0.000 \\
\hline
\end{tabular}

Berdasar hasil dari hasil nilai P value yang menunjukkan angka 0.301 , dengan demikian tidak ada hubungan antara utilitarian value dengan behavioural intentions, menggambarkan bahwa niali-nilai manfaat yang terdapat pada restorant fast food ternyata tidak mempengaruhi pelanggan untuk kembali, merekomendasi maupun kunjungan kembali pelanggan pada restorant fast food.Hal ini juga nampak dari hasil † statistic, yang menunjukkan hubungan kedua variabel juga tidak signifikan.

\section{Kesimpulan}

Berdasarkan hasil dari pengolahan alat uji statistic, Behavioural Intentions, Hedonic Valve, Kepuasan Konsumen dan Utilitarian Value, berupa Part Least Square (PLS), menunjukkan bahwa:

Berdasar uji t statistic, terdapat hubungan yang signifikan yaitu hubungan antara: Hedonic value dengan Behavioural intentions, Hedonic value dengan Kepuasan konsumen, Kepuasan konsumen dengan Behavioural intentions, utilitarian value dengan Kepuasan konsumen. Sementara hubungan utilitarian value dengan behavioural intentions tidak signifikan, menggambarkan bahwa nilai-nilai manfaat yang terdapat pada restorant fast food ternyata tidak mempengaruhi pelanggan untuk kembali, merekomendasi maupun kunjungan kembali pelanggan pada restorant fast food.

Berdasar $\mathrm{P}$ value menunjukkan hubungan yang signifikan yaitu hubungan antara: Hedonic value dengan Behavioural intentions, Hedonic value dengan Kepuasan konsumen, 


\section{Jurnal Manajemen Teori dan Terapan \\ Tahun 11. No. 1, April 2018}

Kepuasan konsumen dengan Behavioural intentions, utilitarian value dengan Kepuasan konsumen. Sementara itu tidak ada hubungan antara utilitarian value dengan behavioural intentions, hal ini menggambarkan bahwa niali-nilai manfaat yang terdapat pada restorant fast food ternyata tidak mempengaruhi pelanggan untuk kembali, merekomendasi maupun kunjungan kembali pelanggan pada restorant fast food.Kontribusi penelitian ini untuk teori melalui pengembangan nilai kepuasan konsumen yaitu hedonic dan utilitarian.

\section{Keterbatasan dan Saran}

Keterbatasan dalam penelitian ini adalah berupa responden yang digunakan terkait dengan pola pemilihan responden dengan status yang berbeda dan heterogen. Saran untuk penelitian berikutnya, peneliti dapat menggunakan responden yaitu mahasiswa dalam sebuah perguruan tinggi dengan satu fakultas. Pelaksaan pengisian kuesioner dapat dilakukan dalam satu kelas yang sama dan melakukan pengisian kuesioner dalam waktu yang bersamaan. Disamping itu, untuk penelitian berikutnya dapat memasukkan variabel control seperti misalnya berupa variabel kontrol "gender" atau "tingkat penghasilan".

\section{Daftar Pustaka}

Arnold, M.J. and Reynolds, K.E. 2003. "Hedonic shopping motivations", Journal of Retailing 79( 2): 77-95.

Babin, B.J. and Attaway, J.S. 2000. "Atmospheric affect as a tool for creating value and gaining share of customer", Journal of Business Research 49 (2): 91-99.

Babin, B.J., Darden, W.R. and Griffin, M. 1994. "Work and/or fun: measuring hedonic and utilitarian shopping value", Journal of Consumer Research 20 (4): 644-656.

Chen, C. and Tsai, D.C. 2007. "How destination image and evaluative factors affect behavioral intentions?", Tourism Management 28 (4): 11 115-1122.

Gede Wira Kusuma, Syafiie I., Atim D. 2013. The influence of hedonic shopping on buying decision wih gender as dummy variable, Europen Journal of Business and Management ISSN 2222-1905 5 (31).

Hair, J.H., Ringle, C.M. and Sarstedt, M. 2011. "PLS-SEM: indeed a silver bullet", Journal of Marketing Theory and Practice 19(2): 139-151.

Imam Ghozali dan Hengky Latan, 2014. Partial Least Squares konsep, metode dan aplikasi, Badan penerbit-Universitas Diponegoro, Semarang.

McDougall, G.H.G. and Levesque, T. 2000, "Customer satisfaction with services: putting perceived valueintotheequation", Journal of ServicesMarketing 14(5):392

Nejati Mehran and Moghaddam, 2013. The effect of hedonic and utilitarian values on 


\section{Arief Sosiawan}

\section{Kadek Oka Swartana}

satisfaction and behavioural intentions for dining in fast-casual restaurants in Iran, British Food Journal $115(11)$

Ritzer, G. 2001. Explorations in the Sociology of Consumption: Fast Food, Credit Cards and Casino, Sage, London.

Ryu, K., Han, H. and Jang, S.S. 2010."Relationships among hedonic and utilitarian values, satisfactionand behavioral intentions in the fast-casual restaurant industry", International Journal of Contemporary Hospitality Management 22(3) :416-

Verhagen Tibert and DolenW.V. 2011 The influence of online store beliefs on consumer online impulse buying: A model and empirical application, Information \& Management 48. 320-327 